Article

\title{
A Novel Benzo[f][1,7]Naphthyridine Produced by Streptomyces Albogriseolus from Mangrove Sediments
}

\author{
Xiao-Ling Li ${ }^{1,3, \dagger}$, Min-Juan Xu ${ }^{2, \dagger}$, Yi-Lei Zhao ${ }^{1}$ and Jun $\mathrm{Xu}^{1, *}$
}

1 Key Laboratory of MOE for Microbial metabolism and School of Life Science \& Biotechnology, State Key Laboratory of Ocean Engineering, Shanghai JiaoTong University, Shanghai 200240, China

2 Key Laboratory of Systems Biomedicine, Shanghai Center for Systems Biomedicine, Shanghai Jiao Tong University, Shanghai 200240, China

3 Key Laboratory of Marine Biogenetic Resources, the Third Institute of Oceanography SOA, Xiamen, Fujian 361005, China

$\dagger$ These authors contributed equally to this work.

* Author to whom correspondence should be addressed; E-Mail: xujunn@sjtu.edu.cn; Tel.: +86-021-34207208; Fax: +86-021-34207205.

Received: 24 October 2010; in revised form: 30 November 2010/Accepted: 7 December 2010/ Published: 15 December 2010

\begin{abstract}
Mangrove Streptomyces represent a rich source of novel bioactive compounds in medicinal research. A novel alkaloid, named 1- $N$-methyl-3-methylamino-[ $N$-butanoic acid3'-(9'-methyl-8'-propen-7'-one)-amide]-benzo[f][1,7]naphthyridine-2-one (1) was isolated from Streptomyces albogriseolus originating from mangrove sediments. The structure of compound 1 was elucidated by extensive spectroscopic data analyses and verified by the ${ }^{13} \mathrm{C}-\mathrm{NMR}$ calculation at the B3LYP/6-311+G(2d,p) level of theory.
\end{abstract}

Keywords: Streptomyces albogriseolus; mangrove; benzo[f][1,7]naphthyridine

\section{Introduction}

Mangrove sediments, which consisting of rich organic matter and salts represent some of the most complex microbial habitats on Earth. Culture independent molecular analysis has been intensively used to detect bacterial communities in mangrove sediments. At least eight different bacterial phyla 
including actinobacteria were detected in $16 \mathrm{~S}$ rRNA gene libraries constructed using a mangrove sediment of Sundarban, India [1]. Groups of actinobacteria strains were isolated from sediments collected from the national mangrove reserve in the Fujian Province of China and at least two novel Streptomyces species, S. xiamenensis [2] and S. avicenniae [3], were identified. The immense and untapped microbial biodiversity in the mangrove ecosystem is a promising resource for natural product studies. The actinobacterial strains that are subjected to the periodical changes in environmental factors seen in mangrove forests, such as salinity and tidal gradients, are believed to be effective selectors for metabolic pathway adaptations that could generate unique metabolites. Previous investigation on secondary metabolites from mangrove endophytes provided a number of new bioactive compounds [4-8]. Streptomyces albogriseolus is well-known for producing novel secondary metabolites and possessing good bioactivity. For instance, echinosporins isolated from marine-derived S. albogriseolus were found to be cell cycle inhibitors, apoptosis inducers and potential anti-tumor agents [9]. Antibiotics, namely cephamycin $\mathrm{C}$, toyocamycin and neomycin complex, were also produced by the strain $[10,11]$. Thienodolin with its unique chloro-substituted structure was used as a plant growth-regulating substance [12]. A mangrove-derived S. albogriseolus was isolated from the sediments and its potential pharmaceutical applications were surveyed both genetically and chemically. This strain produced a novel benzonaphthyridine alkaloid (see Figure 1). In this paper, we report the structural elucidation of a new alkaloid identified as 1- $N$-methyl-3-methylamino-[ $N$-butanoic acid-3'-(9'-methyl- $8^{\prime}$-propen- $7^{\prime}$ one)-amide]-benzo[f][1,7]naphthyridine-2-one (1) by extensive spectroscopic data analyses and the ${ }^{13} \mathrm{C}-\mathrm{NMR}$ calculations at the B3LYP/6-311+G(2d,p) level of theory.

Figure 1. Novel benzonaphthyridine alkaloid 1 isolated from S. albogriseolus.

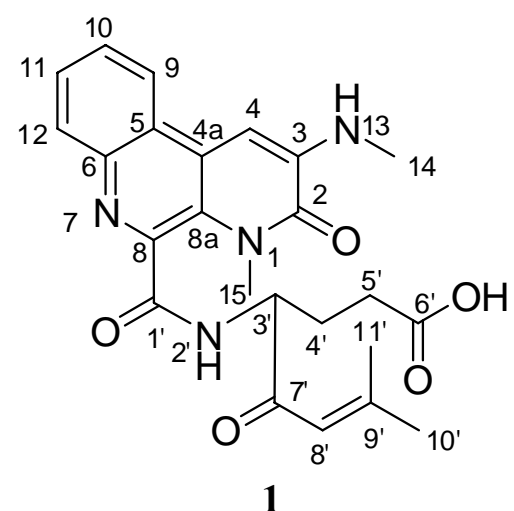

\section{Results and Discussion}

Compound $\mathbf{1}$ was isolated as an yellow amorphous powder and its molecular formula was determined to be $\mathrm{C}_{24} \mathrm{H}_{26} \mathrm{~N}_{4} \mathrm{O}_{5}$ on the basis of HRESIMS analysis $\left(451.2043[\mathrm{M}+\mathrm{H}]^{+}\right.$, calcd. for $\mathrm{C}_{24} \mathrm{H}_{27} \mathrm{~N}_{4} \mathrm{O}_{5}, m / z 451.1981$ ), requiring fourteen degrees of unsaturation. The special bright red color of 1 on TLC after application of Dragendorff's reagent is one of the obvious features of alkaloids, which was in accordance with the HRESIMS result. The UV maxima observed at 250, 380, $525 \mathrm{~nm}$ indicated a highly conjugated system. The IR absorptions at 3,427, 1,631, 1,609, 1,562 $\mathrm{cm}^{-1}$ suggested the presence of hydroxyl, amide carbonyl and aromatic groups, respectively. In the ${ }^{1} \mathrm{H}-\mathrm{NMR}$ spectrum, a 
four-proton spin system with signals at $\delta_{\mathrm{H}} 8.63(1 \mathrm{H}, \mathrm{d}, J=8.3 \mathrm{~Hz}), 7.68(1 \mathrm{H}, \mathrm{dd}, J=8.3,1.1 \mathrm{~Hz})$, $7.72(1 \mathrm{H}, \mathrm{dd}, J=8.4,1.1 \mathrm{~Hz})$, and $7.98(1 \mathrm{H}, \mathrm{d}, J=8.4 \mathrm{~Hz})$, as well as a singlet aromatic proton at $\delta_{\mathrm{H}}$ $7.28(1 \mathrm{H}, \mathrm{s})$ were detected (See Table 1$)$. Carbon signals of the ${ }^{13} \mathrm{C}-\mathrm{NMR}$ spectrum consisted of seventeen aromatic carbons, including six carbonyl groups (see Table 1) which supported the presence of a benzonaphthyridine moiety. The HMBC correlations from $\mathrm{H}-9(8.63, \mathrm{~d}, J=8.3 \mathrm{~Hz})$ to C-6 $(142.0, \mathrm{~s})$, C-11 (128.6, d) and from H-12 (7.98, d, $J=8.4 \mathrm{~Hz})$ to C-5 $(123.2, \mathrm{~s}), \mathrm{C}-10(127.5, \mathrm{~d})$ suggested the benzyl ring was connected to the naphthyridine ring (see Figure 2). HMBC correlations observed from $\mathrm{H}-4(7.28, \mathrm{~s})$ to $\mathrm{C}-2(157.9, \mathrm{~s}), \mathrm{C}-4 \mathrm{a}(123.0, \mathrm{~s})$ and C-8a $(125.8, \mathrm{~s})$ indicated that the carbonyl group is placed on C-2. Based on the HMBC correlations from NH-13 (6.92, q, $J=5.1 \mathrm{~Hz})$ to C-2 $(157.9, \mathrm{~s})$, C-4 (95.8, d) and $\mathrm{CH}_{3}-14$ (29.9 q), and the NOE interaction between $\mathrm{H}_{3}-14$ and $\mathrm{H}-4$, the methylaminogroup was positioned at C-3 (see Figure 2). Key NOE correlation between H-9 and H-4 confirmed the benzo[f][1,7]naphthyridine portion. In the aliphatic region, ${ }^{1} \mathrm{H}-{ }^{1} \mathrm{H}$ COSY spectrum revealed the signals at $\delta_{\mathrm{H}} 4.57\left(1 \mathrm{H}, \mathrm{ddd}, \mathrm{H}-3^{\prime}\right), 1.89\left(1 \mathrm{H}\right.$, dddd; $\left.2.10,1 \mathrm{H}, \mathrm{m}, \mathrm{H}_{2}-4^{\prime}\right)$ and $2.39\left(2 \mathrm{H}, \mathrm{m}, \mathrm{H}_{2}-5^{\prime}\right)$ were adjacent to each other. $\mathrm{HMBC}$ correlation between $\mathrm{H}_{2}-5^{\prime}$ and the carboxyl carbon $\mathrm{C}-6^{\prime}\left(\delta_{\mathrm{C}} 174.0\right)$ coupled with the presence of an exchangeable proton at $\left(\delta_{\mathrm{H}} 12.23\right)$, indicated a carboxylic acid group on C-5'. A modified isoprenyl group consisting of an olefinic proton at $\delta_{\mathrm{H}} 6.46\left(\mathrm{H}-8^{\prime}, \mathrm{s}\right)$ correlated to $\mathrm{C}-7^{\prime}(198.4, \mathrm{~s})$, C-9' $(157.8, \mathrm{~s})$ in the HMBC spectrum, ending the two methyls at $\delta_{\mathrm{H}} 1.94\left(\mathrm{H}_{3}-10^{\prime}, \mathrm{s}\right)$ and $2.16\left(\mathrm{H}_{3}-11^{\prime}, \mathrm{s}\right)$, is attached to the $\mathrm{C}-3^{\prime}$ position of this aliphatic chain as indicated by the HMBC correlation between $\mathrm{H}-3^{\prime}$ to $\mathrm{C}-7^{\prime}$. The NOE interaction between NH-2' (9.24, d, $\left.J=7.4 \mathrm{~Hz}\right), \mathrm{H}-3^{\prime}$ and $\mathrm{H}_{3}-15$ (3.71, s) suggested the aliphatic region and benzonaphthyridine portion was connected by the amide functional group (see Figure 2).

Figure 2. Key COSY, HMBC and NOE correlations of compound 1.

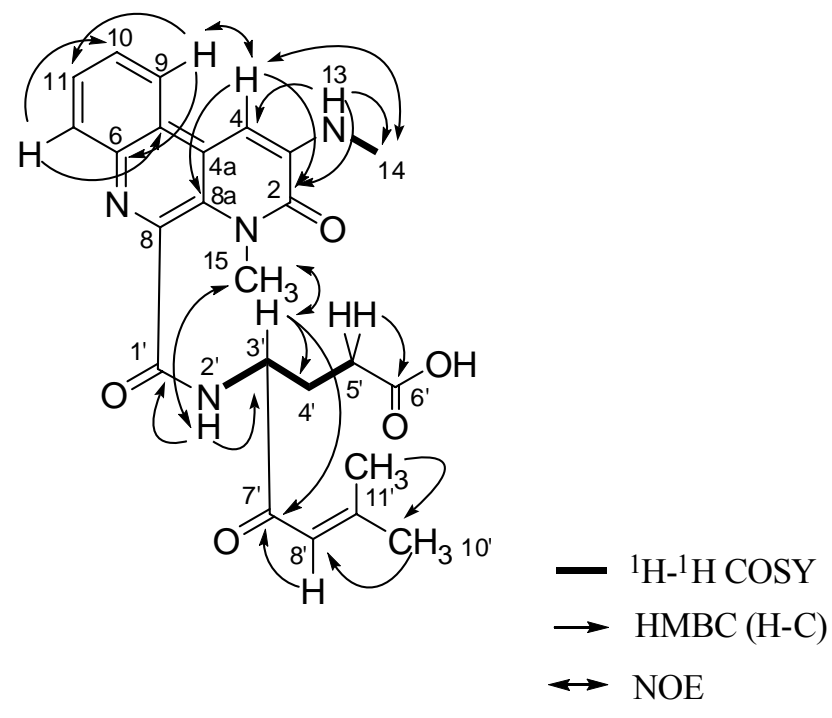


Table 1. ${ }^{1} \mathrm{H}$ - and ${ }^{13} \mathrm{C}-\mathrm{NMR}$ data of compound $\mathbf{1}^{\mathrm{a}}$.

\begin{tabular}{|c|c|c|}
\hline \multirow{2}{*}{ Position } & \multicolumn{2}{|l|}{1} \\
\hline & $\delta_{H}$ & $\boldsymbol{\delta}_{\mathrm{C}}$ \\
\hline 1 & -- & -- \\
\hline 2 & -- & $157.9 \mathrm{~s}$ \\
\hline 3 & -- & $142.2 \mathrm{~s}$ \\
\hline 4 & $7.28 \mathrm{~s}$ & $95.8 \mathrm{~d}$ \\
\hline $4 a$ & -- & $123.0 \mathrm{~s}$ \\
\hline 5 & -- & $123.2 \mathrm{~s}$ \\
\hline 6 & -- & $142.0 \mathrm{~s}$ \\
\hline 7 & -- & -- \\
\hline 8 & -- & $145.3 \mathrm{~s}$ \\
\hline $8 a$ & -- & $125.8 \mathrm{~s}$ \\
\hline 9 & $8.63 \mathrm{~d}(8.3)$ & $123.4 \mathrm{~d}$ \\
\hline 10 & $7.68 \mathrm{dd}(8.3,1.1)$ & $127.5 \mathrm{~d}$ \\
\hline 11 & 7.72 dd $(8.4,1.1)$ & $128.6 \mathrm{~d}$ \\
\hline 12 & $7.98 \mathrm{~d}(8.4)$ & $129.5 \mathrm{~d}$ \\
\hline 13-NH & $6.92 \mathrm{q}(5.1)$ & -- \\
\hline 14 & $2.98 \mathrm{~d}(5.0)$ & $29.9 \mathrm{q}$ \\
\hline 15 & $3.71 \mathrm{~s}$ & $34.9 \mathrm{q}$ \\
\hline $1^{\prime}$ & -- & $169.2 \mathrm{~s}$ \\
\hline $2^{\prime}-\mathrm{NH}$ & $9.24 \mathrm{~d}(7.4)$ & -- \\
\hline $3^{\prime}$ & $4.57 \mathrm{ddd}(8.4,7.3,4.8)$ & $58.8 \mathrm{~d}$ \\
\hline $4^{\prime}$ & $\begin{array}{c}2.10 \mathrm{~m} \\
1.89 \text { dddd }(14.6,8.4,8.4,8.4)\end{array}$ & $25.9 \mathrm{t}$ \\
\hline $5^{\prime}$ & $2.39 \mathrm{~m}$ & $30.8 \mathrm{t}$ \\
\hline $6^{\prime}$ & -- & $174.0 \mathrm{~s}$ \\
\hline $7^{\prime}$ & -- & $198.4 \mathrm{~s}$ \\
\hline $8^{\prime}$ & $6.46 \mathrm{~s}$ & $121.5 \mathrm{~d}$ \\
\hline $9^{\prime}$ & -- & $157.8 \mathrm{~s}$ \\
\hline $10^{\prime}$ & $1.94 \mathrm{~s}$ & $21.1 \mathrm{q}$ \\
\hline $11^{\prime}$ & $2.16 \mathrm{~s}$ & $28.0 \mathrm{q}$ \\
\hline $6^{\prime}-\mathrm{OH}$ & $12.23 \mathrm{~s}$ & -- \\
\hline
\end{tabular}

The structure of 1 was further confirmed by interpretation of the fragmentation pattern in HPLCESI-MS/MS. Ions from the benzonaphthyridine portion $(238 \mathrm{u})$ and the aliphatic region $(212 \mathrm{u})$ were found, representing the cleavage of the bond between $\mathrm{C}-1^{\prime}$ and $\mathrm{C}-8$. The fragmentation pathway of benzonaphthyridine was found to result in the loss of methyl group and carbonyl group, successively, corresponding to the $223 \mathrm{u}$ and $195 \mathrm{u}$ in mass spectra. The mass fragment of $169 \mathrm{u}$ displayed the loss of amide group from the metastable aliphatic ion. Thus, compound 1 was determined as 1- $N$-methyl-3methylamino-[ $N$-butanoic acid-3'-(9'-methyl-8'-propen-7'-one)-amide]benzo[f][1,7]naphthyridine-2-one (1).

Compound 1 possesses a fused tricyclic heteroaromatic system, which belongs to diazaphenathrene family. Considering such structural character, calculation of ${ }^{13} \mathrm{C}-\mathrm{NMR}$ shifts has been applied as a useful tool for the structural elucidation, e.g. in the example of samoquasine A [13]. Here calculations 
of the theoretical ${ }^{13} \mathrm{C}-\mathrm{NMR}$ spectrum were carried out with the Gaussian 09 software package [14], using a simplified model in which the aliphatic chain was replaced with aldehyde. Geometry optimizations and frequency calculations were performed at the B3LYP/6-31G(d) level of theory and the optimized structures were verified as true minima with no imaginary frequency [15]. ${ }^{13} \mathrm{C}-\mathrm{NMR}$ chemical shifts were estimated with the GIAO-based method [16] at the B3LYP/6-311 + G(2d,p), using a benzene reference of $128.5 \mathrm{ppm}$. The calculated results were in good agreement with the experimental carbon resonance assignments and an unambiguous assignment of the ${ }^{13} \mathrm{C}-\mathrm{NMR}$ chemical shifts was achieved by the comparison of the computed ${ }^{13} \mathrm{C}$-NMR data with the experimental data (see Table 2). The deviation was found to be less than $5.5 \mathrm{ppm}$, and averaged $2.3 \mathrm{ppm}$.

Table 2. Comparison of the calculated vs. experimental carbon resonances for the benzo[f][1,7]naphthyridine part of $\mathbf{1}$.

\begin{tabular}{cccc}
\hline Carbon & $\boldsymbol{\delta}_{\text {expt. }}$ & $\boldsymbol{\delta}_{\text {cald. }}$ & $\boldsymbol{\Delta}\left(\boldsymbol{\delta}_{\text {cald. }}-\boldsymbol{\delta}_{\text {expt. }}\right)$ \\
\hline 2 & $157.9 \mathrm{~s}$ & 158.8 & +0.9 \\
3 & $142.2 \mathrm{~s}$ & 141.5 & +0.7 \\
4 & $95.8 \mathrm{~d}$ & 93.2 & +2.4 \\
$4 \mathrm{a}$ & $123.0 \mathrm{~s}$ & 127.4 & +4.4 \\
5 & $123.2 \mathrm{~s}$ & 123.9 & +0.7 \\
6 & $142.0 \mathrm{~s}$ & 146.1 & +4.1 \\
8 & $145.3 \mathrm{~s}$ & 144.3 & +1.0 \\
$8 \mathrm{a}$ & $125.8 \mathrm{~s}$ & 129.2 & +3.4 \\
9 & $123.4 \mathrm{~d}$ & 120.7 & +2.7 \\
10 & $127.5 \mathrm{~d}$ & 128.2 & +0.7 \\
11 & $128.6 \mathrm{~d}$ & 127.7 & +1.1 \\
12 & $129.5 \mathrm{~d}$ & 135.0 & +5.5 \\
\hline
\end{tabular}

The benzonaphthyridines are unique alkaloids with diverse bioactivities. The marine environment seems to be a rich source of such molecules. Aaptamines were isolated from a marine sponge Aaptos sp. [17-19], which exhibited different bioactivities, e.g. competitive antagonist of $\alpha$-adrenoceptors in vascular smooth muscles [20], activator of p21 promoter in a p53-independent manner [21], antineoplastic [22], antivirus and anticancer properties [23], hence triggering major interest in its total synthesis [24]. Another type of 2,7-naphthyridine alkaloids, the lophocladines and subarine were isolated from the marine red alga Lophocladia sp. [25] and a Singaporean ascidian, respectively [26]. In this work, benzo[f][1,7]naphthyridine was identified as the first example of this class found among mangrove related microbial metabolites. A series of such type of alkaloids was further detected by Dragendorff's reagent on TLC and by HPLC-MS technique. An analogue of 1 possessing the molecular formula of $\mathrm{C}_{24} \mathrm{H}_{28} \mathrm{~N}_{4} \mathrm{O}_{6}$ on the basis of HRESIMS analysis (469.1911 [M $\left.+\mathrm{H}\right]^{+}$, calcd. for $\mathrm{C}_{24} \mathrm{H}_{29} \mathrm{~N}_{4} \mathrm{O}_{6}, m / z$ 469.2087) and similar UV profile was found in trace amounts, so more derivatives of benzo[f][1,7]naphthyridine seem to be produced by the $S$. albogriseolus, but their low productivity in fermentation hindered further chemical and pharmaceutical investigations.

Primary bioinformatics analysis of the draft genome sequence of the producer strain, $S$. albogriseolus has revealed the existence of at least two putative antibiotic biosynthetic gene clusters, including polyketide synthases and key components in phenazines biosynthesis in the genome 
(unpublished data). Resolving the biosynthesis pathway of benzonaphthyridine will probably clarify the real source of such compounds in the microorganism. Considering the novelty of structure and the minor amounts isolated, the genetic manipulation of the biosynthetic genes might offer us another opportunity for searching for bioactive novel leading compounds besides synthetic methods and for producing such compounds in large amounts for medicinal research.

\section{Experimental}

\subsection{General}

${ }^{1} \mathrm{H}$ - and ${ }^{13} \mathrm{C}-\mathrm{NMR}$ spectra were recorded with Bruker DRX-500 and Avance III-600 NMR spectrometers with TMS as an internal standard. Chemical shifts $(\delta)$ are expressed in parts per million (ppm) and coupling constants $(J)$ are reported in Hertz $(\mathrm{Hz})$. The IR spectra were recorded with a Bruker EQUINOX 55 FT spectrometer. Optical rotations were recorded on a JASCO P-2000 polarimeter. HR-ESI-MS spectra were measured on a Waters Quattro Premier XE mass spectrometer (Waters Corp., Millford, MA, USA). ESI-MS spectra were measured on a Bio ESI-Q-TOF mass spectrometer (Bruker Daltonik $\mathrm{GmbH}$ ). Chromatographic separation for HPLC-ESI-MS/MS was carried out on Agilent ZOR BAS SB-C18 (ODS, $1.8 \mu \mathrm{m}, 2.1 \times 50 \mathrm{~mm}$ ). Mass spectrometry for HPLCESI-MS/MS was carried out on a Agilent1200 MS Q-TOF 6530. CD spectra were taken on a J-815 spectropolarimeter (JASCO, Gross-Umstadt, Germany) at room temperature. Column chromatography was performed with silica gel (200-300 mesh, Qingdao Marine Chemical, Inc., Qingdao, P. R. China), silica gel H (10-40 $\mu \mathrm{m}$, Qingdao), Sephadex LH-20 (40-70 $\mu \mathrm{m}$, Amersham Pharmacia Biotech AB, Uppsala, Sweden) and Lichroprep reversed-phase RP-18 silica gel (40-63 $\mu \mathrm{m}$, Merck, Darmstadt, Germany). Preparative TLC (1.0-1.5 mm) was conducted with glass-pre-coated silica gel GF254 (Qingdao), and spots were visualized under UV light. The chemical reagents used for chromatography were purchased from Shanghai Chemical Works Co. Ltd. (Shanghai). Analytical HPLC was carried out on an Agilent XDB-C18 column $(4.6 \times 150 \mathrm{~mm}, 5 \mu \mathrm{m})$, flow $1 \mathrm{~mL} / \mathrm{min}$, UV detection $(254 \mathrm{~nm})$. Organic solvents for HPLC were analytical grade were purchased from Merck KGaA (Darmstadt, Germany).

\subsection{Strain Isolation, Characterization, and Cultivation}

The strain was isolated from the sediment collected in the national mangrove reserve in Fujian province of China, where Avicennia marina grows as the dominant species. The collected sediment was air dried and ground up. Soil samples $(1 \mathrm{~g})$ were mixed with sterile water $(9 \mathrm{~mL})$ and then diluted to $10^{-6}$. The diluted suspension $(100 \mu \mathrm{L})$ was transferred to Gause's synthetic agar [soluble starch $20.0 \mathrm{~g} / \mathrm{L}, \mathrm{K}_{2} \mathrm{HPO}_{4} 0.5 \mathrm{~g} / \mathrm{L}, \mathrm{MgSO}_{4} \cdot 7 \mathrm{H}_{2} \mathrm{O} 0.5 \mathrm{~g} / \mathrm{L}, \mathrm{NaCl} 0.5 \mathrm{~g} / \mathrm{L}, \mathrm{NaNO}_{3} 1.0 \mathrm{~g} / \mathrm{L}, \mathrm{FeSO}_{4} 0.01 \mathrm{~g} / \mathrm{L}$, agar $2 \%, 25 \mu \mathrm{g} / \mathrm{mL}$ nalidixic acid for inhibiting the grow of bacteria, $\mathrm{pH} 7.2]$ then incubated at $28{ }^{\circ} \mathrm{C}$ for 10-15 days. Purified single colonies were classified according to colony morphology. One isolated strain MGR072 was assigned as Streptomyces albogriseolus by 16S rRNA gene sequence analysis. The production culture was carried out in a $30 \mathrm{~L}$ of ISP 3 media $(20 \mathrm{~g}$ oats per $1 \mathrm{~L}$ media, $1.5 \%$ agar, $\mathrm{pH}$ 7.2-7.4). It was grown for 12 days at $28 \pm 1{ }^{\circ} \mathrm{C}$. 


\subsection{Extraction and Isolation}

The production culture of $S$. albogriseolus was extracted at room temperature overnight with a solvent mixture of ethyl acetate/methanol/acetic acid (about 5 L, 80:15:5, v:v:v). The supernatant was filtered and the residue was then extracted twice more as described above. The supernatants were combined and concentrated under vacuum at $37{ }^{\circ} \mathrm{C}$ in order to remove the organic phase. The remaining aqueous solution was partitioned four times with ethyl acetate (about $2 \mathrm{~L}, 1: 1, \mathrm{v}: \mathrm{v}$ ). The upper layer was collected to afford a crude extract $(6 \mathrm{~g})$ which was subjected to column chromatography on RP-18, eluted by mixture of methanol and $\mathrm{H}_{2} \mathrm{O}$ [gradient from methanol, 30:70 (v:v, 2 L), 50:50 (v:v, 2 L), 70:30 (v:v, 2 L) to $\mathrm{H}_{2} \mathrm{O}$ ], to afford five fractions Fr. 1-5. Fr. 3 (178 mg) was collected and further purified by repeated Sephadex LH-20 column chromatography, eluted with methanol $(700 \mathrm{~mL} \times 1,250 \mathrm{~mL} \times 2)$ first and then seperated again by Sephadex LH-20, using acetone $(250 \mathrm{~mL} \times 1)$ as solvent system. Subfraction 3-2 $(13 \mathrm{mg})$ was identified as the target fraction by TLC which then applied to column chromatography on silica gel, eluted with chloroform/methanol [gradient from 50:1 (v:v, $100 \mathrm{~mL})$ to $30: 1(\mathrm{v}: \mathrm{v}, 60 \mathrm{~mL})$ ], to afford 1-N-methyl-3-methylamino-[N-butanoic acid3'-(9'-methyl-8'-propen-7'-one)-amide]-benzo[f][1,7]naphthyridine-2-one (1, $5 \mathrm{mg})$. The compound was analyzed by HPLC after separation. Compound $1(\sim 1 \mathrm{mg} / \mathrm{mL})$ was detected at the retention time of $31.7 \mathrm{~min}$ by analytical HPLC (Agilent XDB-C18, $4.6 \times 150 \mathrm{~mm}, 5 \mu \mathrm{m}$ ), with the following gradient: $\mathrm{H}_{2} \mathrm{O}(\mathrm{A}) / \mathrm{MeOH}(\mathrm{B}): 0 \min 10 \% \mathrm{~B}, 10 \min 10 \% \mathrm{~B}, 40 \min 100 \% \mathrm{~B}$, at flow rate of $1 \mathrm{~mL} / \mathrm{min}$. Yellow amorphous powder; $[\alpha]_{D}^{22}:-72^{\circ}(c 0.0017, \mathrm{MeOH}) ; \mathrm{UV} \lambda_{\max }(\mathrm{MeOH}) 250,380$, $525 \mathrm{~nm} ; \mathrm{CD}(\mathrm{MeOH}): \Delta \varepsilon_{195}+0.6, \Delta \varepsilon_{201}-0.6, \Delta \varepsilon_{205}+0.3, \Delta \varepsilon_{220}+0.4, \Delta \varepsilon_{227}+0.3, \Delta \varepsilon_{231}-0.1, \Delta \varepsilon_{237}$ $+0.4, \Delta \varepsilon_{249} 0.2$; IR (KBr) $v_{\max } 3,427,2,927,1,631,1,609,1,562,1,415,1,350,1,257,762,615 \mathrm{~cm}^{-1}$; ${ }^{1} \mathrm{H}-$ and ${ }^{13} \mathrm{C}-\mathrm{NMR}$ data, see Table 1; ESIMS $m / z$ 451.2 $[\mathrm{M}+\mathrm{H}]^{+}$; HRESIMS $m / z 451.2043[\mathrm{M}+\mathrm{H}]^{+}$, (calcd. for $\mathrm{C}_{24} \mathrm{H}_{27} \mathrm{~N}_{4} \mathrm{O}_{5}, m / z$ 451.1981), $449.1622[\mathrm{M}-\mathrm{H}]^{-}$, (calcd. for $\mathrm{C}_{24} \mathrm{H}_{25} \mathrm{~N}_{4} \mathrm{O}_{5}, m / z$ 449.1825); HPLC-ESI-MS/MS $m / z 473.1745[\mathrm{M}+\mathrm{Na}]^{+}, 923.3739[2 \mathrm{M}+\mathrm{Na}]^{+}, 238.0986,223.0740,212.0804$, 210.0839, 195.0789, 184.0596, 181.0752, 169.0764 .

\subsection{Computational Methods}

Structure optimization was accomplished with the program package Gaussian 09 using the hybrid DFT functional B3LYP together with Pople's 6-31(d) and 6-311 + G(2d,p) basis sets.

\section{Conclusions}

A novel benzonaphthyridine alkaloid has been isolated from a mangrove-derived $S$. albogriseolus. The compound has been identified as [ $N$-butanoic acid-3'-(9'-methyl- $8^{\prime}$-propen-7'-one)-amide]benzo[f][1,7]naphthyridine-2-one (1) by extensive spectroscopic data analyses and quantum chemical carbon resonance calculations. Mangrove Streptomyces represent a rich source for novel bioactive compounds in medicinal research. 


\section{Acknowledgements}

We are grateful to $\mathrm{Xi}$ Huang and Yi Yang for technical support during the HPLC-MS/MS measurement, to Zhiwei Deng for the NMR measurements, and Instrumental Analysis Center of Shanghai Jiao Tong University for the IR, optical rotation and CD tests. The work was supported by grants from the National Science Foundation of China (30901845), China Ocean Mineral Resources Research and Development Association fund (DYXM-115-02-2-8) and the National High-tech R\&D Program of China (2007AA091904). The project was sponsored by SRF for ROCS, SEM, and China State Key Laboratory of Ocean Engineering (GKZD010045), and by Research Fund for the New Teacher Program of Higher Education of China (20090001120047).

\section{References and Notes}

1. Ghosh, A.; Dey, N.; Bera, A.; Tiwari, A.; Sathyaniranjan, K.; Chakrabarti, K.; Chattopadhyay, D. Culture independent molecular analysis of bacterial communities in the mangrove sediment of Sundarban, India. Saline Systems 2010, 6, 1.

2. Xu, J.; Wang, Y.; Xie, S.J.; Xu, J.; Xiao, J.; Ruan, J.S. Streptomyces xiamenensis sp. nov., isolated from mangrove sediment. Int. J. Syst. Evol. Microbiol. 2009, 59, 472-476.

3. Xiao, J.; Wang, Y.; Luo, Y.; Xie, S.J.; Ruan, J.S.; Xu, J. Streptomyces avicenniae sp. nov., a novel actinomycete isolated from the rhizosphere of the mangrove plant Avicennia mariana. Int. $J$. Syst. Evol. Microbiol. 2009, 59, 2624-2628.

4. Guan, S.; Grabley, S.; Groth, I.; Lin, W.; Christner, A.; Guo, D.; Sattler, I. Structure determination of germacrane-type sesquiterpene alcohols from an endophyte Streptomyces griseus subsp. Magn. Reson. Chem. 2005, 43, 1028-1031.

5. Guan, S.H.; Sattler, I.; Lin, W.H.; Guo, D.A.; Grabley, S. p-Aminoacetophenonic acids produced by a mangrove endophyte: Streptomyces griseus subsp. J. Nat. Prod. 2005, 68, 1198-1200.

6. Lin, W.; Li, L.; Fu, H.; Sattler, I.; Huang, X.; Grabley, S., New cyclopentenone derivatives from an endophytic Streptomyces sp. isolated from the mangrove plant Aegiceras comiculatum. J. Antibiot (Tokyo) 2005, 58, 594-598.

7. Wang, F.; Xu, M.; Li, Q.; Sattler, I.; Lin, W. p-Aminoacetophenonic Acids Produced by a Mangrove Endophyte Streptomyces sp. (strain HK10552). Molecules 2010, 15, 2782-2790.

8. Xu, M.; Gessner, G.; Groth, I.; Lange, C.; Christner, A.; T., B.; Deng, Z.; Li, X.; Heinemann, S.H.; Grabley, S.; Bringmann, G.; Sattler, I.; Lin, W. Shearinines D-K, new indole triterpenoids from an endophytic Penicillium sp. (strain HKI0459) with blocking activity on large-conductance calcium-activated potassium channels. Tetrahedron 2007, 63, 435-444.

9. Cui, C.B.; Liu, H.B.; Gu, J.Y.; Gu, Q.Q.; Cai, B.; Zhang, D.Y.; Zhu, T.J. Echinosporins as new cell cycle inhibitors and apoptosis inducers from marine-derived Streptomyces albogriseolus. Fitoterapia 2007, 78, 238-240.

10. Stapley, E.O.; Mata, J.M. Antibiotics cephamycin C and toyocamycin by fermentation of Streptomyces albogriseolus. United States Patent 3914158, 1975. 
11. Benedict, R.G.; Shotwell, O.L.; Pridham, T.G.; Lindenfelser, L.A.; Haynes, W.C. The production of the neomycin complex by Streptomyces albogriseolus, nov. sp. Antibiot. Chemother. 1954, 4, 653-656.

12. Kenji, K.; Hiroshi, N.; Kazuo, N.; Yoshiro, O.; Tomio, T. Thienodolin, a new plant growthregulating substance produced by a streptomycete strain: II structure of thienodolin. Biosci. Biotechnol. Biochem. 1993, 57, 636-637.

13. Timmons, C.; Wipf, P. Density functional theory calculation of $13 \mathrm{C}$ NMR shifts of diazaphenanthrene alkaloids: reinvestigation of the structure of samoquasine A. J. Org. Chem. 2008, 73, 9168-9170.

14. Frisch, J.; Trucks, G.W.; Schlegel, H.B.; Scuseria, G.E.; Robb, M.A.; Cheeseman, J.R.; Scalmani, G.; Barone, V.; Mennucci, B.; Petersson, G.A.; Nakatsuji, H.; Caricato, M.; Li, X.; Hratchian, H.P.; Izmaylov, A.F.; Bloino, J.; Zheng, G.; Sonnenberg, J.L.; Hada, M.; Ehara, M.; Toyota, K.; Fukuda, R.; Hasegawa, J.; Ishida, M.; Nakajima, T.; Honda, Y.; Kitao, O.; Nakai, H.; Vreven, T.; Montgomery, J.J.A.; Peralta, J.E.; Ogliaro, F.; Bearpark, M.; Heyd, J.J.; Brothers, E.; Kudin, K.N.; Staroverov, V.N.; Kobayashi, R.; Normand, J.; Raghavachari, K.; Rendell, A.; Burant, J.C.; Iyengar, S.S.; Tomasi, J.; Cossi, M.; Rega, N.; Millam, J.M.; Klene, M.; Knox, J.E.; Cross, J.B.; Bakken, V.; Adamo, C.; Jaramillo, J.; Gomperts, R.; Stratmann, R.E.; Yazyev, O.; Austin, A.J.; Cammi, R.; Pomelli, C.; Ochterski, J.W.; Martin, R.L.; Morokuma, K. Gaussian 2009, Revision A.02; Gaussian Inc.: Wallingford, CT, 2009.

15. Becke, A.D. Density-functional thermochemistry. III. The role of exact exchange. J. Chem. Phys. 1993, 98, 5648-5652.

16. Schuler, R.H.; Albarran, G.; Zajicek, J.; George, M.V.; Fessenden, R.W.; Carmichael, I. On the addition of $\mathrm{OH}$ radicals to the Ipso positions of alkyl-substituted aromatics: Production of 4hydroxy-4-methyl-2,5-cyclohexadien-1-one in the adiolytic oxidation of $p$-Cresol. J. Phys. Chem. A 2002, 106, 12178-12183.

17. Shubina, L.K.; Kalinovsky, A.I.; Fedorov, S.N.; Radchenko, O.S.; Denisenko, V.A.; Dmitrenok, P.S.; Dyshlovoy, S.A.; Krasokhin, V.B.; Stonik, V.A. Aaptamine alkaloids from the Vietnamese sponge Aaptos sp. Nat. Prod. Commun. 2009, 4, 1085-1088.

18. Shaari, K.; Ling, K.C.; Rashid, Z.M.; Jean, T.P.; Abas, F.; Raof, S.M.; Zainal, Z.; Lajis, N.H.; Mohamad, H.; Ali, A.M. Cytotoxic aaptamines from Malaysian Aaptos aaptos. Mar. Drugs 2009, $7,1-8$.

19. Jang, K.H.; Chung, S.C.; Shin, J.; Lee, S.H.; Kim, T.I.; Lee, H.S.; Oh, K.B. Aaptamines as sortase A inhibitors from the tropical sponge Aaptos aaptos. Bioorg. Med. Chem. Lett. 2007, 17, 5366-5369.

20. Ohizumi, Y.; Kajiwara, A.; Nakamura, H.; Kobayashi, J. Alpha-adrenoceptor blocking action of aaptamine, a novel marine natural product, in vascular smooth muscle. J. Pharm. Pharmacol. 1984, 36, 785-786.

21. Aoki, S.; Kong, D.; Suna, H.; Sowa, Y.; Sakai, T.; Setiawan, A.; Kobayashi, M. Aaptamine, a spongean alkaloid, activates p21 promoter in a p53-independent manner. Biochem. Biophys. Res. Commun. 2006, 342, 101-106. 
22. Pettit, G.R.; Hoffmann, H.; Herald, D.L.; McNulty, J.; Murphy, A.; Higgs, K.C.; Hamel, E.; Lewin, N.E.; Pearce, L.V.; Blumberg, P.M.; Pettit, R.K.; Knight, J.C. Antineoplastic agents 491. Synthetic conversion of aaptamine to isoaaptamine, 9-demethylaaptamine, and 4-methylaaptamine. J. Org. Chem. 2004, 69, 2251-2256.

23. Bowling, J.J.; Pennaka, H.K.; Ivey, K.; Wahyuono, S.; Kelly, M.; Schinazi, R.F.; Valeriote, F.A.; Graves, D.E.; Hamann, M.T. Antiviral and anticancer optimization studies of the DNA-binding marine natural product aaptamine. Chem. Biol. Drug Des. 2008, 71, 205-215.

24. Walz, A.J.; Sundberg, R.J. Synthesis of 8-methoxy-1-methyl-1H-benzo[de][1,6]naphthyridin-9-ol (Isoaaptamine) and analogues. J. Org. Chem. 2000, 65, 8001-8010.

25. Gross, H.; Goeger, D.E.; Hills, P.; Mooberry, S.L.; Ballantine, D.L.; Murray, T.F.; Valeriote, F.A.; Gerwick, W.H. Lophocladines, bioactive alkaloids from the red alga Lophocladia sp. J. Nat. Prod. 2006, 69, 640-644.

26. Nilar, N.; Sidebottom, P.J.; Carte, B.K.; Butler, M.S. Three new pyridoacridine type alkaloids from a singaporean ascidian. J. Nat. Prod. 2002, 65, 1198-1200.

Sample Availability: Samples of compound $\mathbf{1}$ are available from authors.

(C) 2010 by the authors; licensee MDPI, Basel, Switzerland. This article is an open access article distributed under the terms and conditions of the Creative Commons Attribution license (http://creativecommons.org/licenses/by/3.0/). 